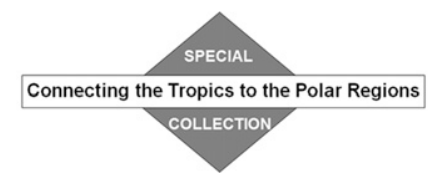

\title{
Rossby Waves Mediate Impacts of Tropical Oceans on West Antarctic Atmospheric Circulation in Austral Winter
}

\author{
XICHEN LI \\ Scripps Institution of Oceanography, University of California, San Diego, San Diego, California \\ DAVID M. Holland AND EDWIN P. GERBER \\ Courant Institute of Mathematical Sciences, New York University, New York, New York \\ CHANGHYUN YOO \\ Department of Atmospheric Science and Engineering, Ewha Womans University, Seoul, South Korea
}

(Manuscript received 7 February 2015, in final form 27 July 2015)

\begin{abstract}
Recent studies link climate change around Antarctica to the sea surface temperature of tropical oceans, with teleconnections from the Pacific, Atlantic, and Indian Oceans making different contributions to Antarctic climate. In this study, the impacts of each ocean basin on the wintertime Southern Hemisphere circulation are identified by comparing simulation results using a comprehensive atmospheric model, an idealized dynamical core model, and a theoretical Rossby wave model. The results herein show that tropical Atlantic Ocean warming, Indian Ocean warming, and eastern Pacific cooling are all able to deepen the Amundsen Sea low located adjacent to West Antarctica, while western Pacific warming increases the pressure to the west of the international date line, encompassing the Ross Sea and regions south of the Tasman Sea. In austral winter, these tropical ocean basins work together linearly to modulate the atmospheric circulation around West Antarctica. Further analyses indicate that these teleconnections critically depend on stationary Rossby wave dynamics and are thus sensitive to the background flow, particularly the subtropical/midlatitude jet. Near these jets, wind shear is amplified, which strengthens the generation of Rossby waves. On the other hand, near the edges of the jets the meridional gradient of the absolute vorticity is also enhanced. As a consequence of the Rossby wave dispersion relationship, the jet edge may reflect stationary Rossby wave trains, serving as a waveguide. The simulation results not only identify the relative roles of each of the tropical ocean basins in the tropical-Antarctica teleconnection, but also suggest that a deeper understanding of teleconnections requires a better estimation of the atmospheric jet structures.
\end{abstract}

\section{Introduction}

Over the past few decades, West Antarctica has experienced dramatic climate changes, including Antarctic Peninsula warming (Vaughan et al. 2001, 2003; Schneider et al. 2012; Pritchard and Vaughan 2007; Pritchard et al. 2012; Shepherd et al. 2012; Bromwich et al. 2013), sea ice redistribution (Yuan and Martinson 2001; Yuan 2004; Liu et al. 2004; Stammerjohn et al. 2008), and accelerated landice melting (e.g., Pritchard and Vaughan 2007; Pritchard

Corresponding author address: Xichen Li, CASPO, Scripps Institution of Oceanography, UC San Diego, 9500 Gilman Drive \#0206, La Jolla, CA 92093-0206.

E-mail: xichenslc@gmail.com et al. 2012). These changes impact on global climate through their contributions to sea level rise (IPCC 2013; Pritchard et al. 2009; Shepherd et al. 2012) and deepocean circulations (Holland and Kwok 2012). The observed West Antarctic climate change is tightly related to Antarctic atmospheric circulation changes (Lefebvre et al. 2004; Lefebvre and Goosse 2005; Sigmond and Fyfe 2010; Stammerjohn et al. 2008; Thompson et al. 2011; Schneider et al. 2012). The southern annular mode (SAM; Thompson and Wallace 2000; Thompson et al. 2000b) is a prominent pattern of the Southern Hemisphere large-scale atmospheric variability, which explains about $20 \%-30 \%$ of sea level pressure (SLP) variability south of $20^{\circ} \mathrm{S}$ (Thompson and Wallace 2000) on monthly and longer time scales. In West Antarctica 
the atmospheric circulation is dominated by a semipermanent low pressure system, the Amundsen Seas low (ASL), (Jacobs and Comiso 1997; Fogt et al. 2011, 2012; Turner et al. 2013; Raphael et al. 2016). The ASL is significantly correlated with the SAM index (Fogt et al. 2012) and serves as one of the three low pressure centers of the SAM.

Previous studies revealed linkages between the interannual variability of Antarctic atmospheric circulation and the tropical Pacific sea surface temperature (SST). Karoly (1989) envisioned that ENSO is associated with a dipole pattern in the zonal-mean atmospheric circulation in the extratropical Southern Hemisphere during austral winter, a feature known as the Pacific-South American (PSA) pattern. Fogt and Bromwich (2006) reported that the teleconnection between ENSO and South Hemisphere atmospheric variability is related to the coupling with the SAM, while the combination of ENSO and SAM can further impact sea ice retreat and advance (Stammerjohn et al. 2008). Although the impact of ENSO on the Antarctic region is found to be very significant during austral winter, several recent studies (Renwick and Revell 1999; Clem and Fogt 2013) have shown that these teleconnections are also robust and important for austral spring Antarctic climate.

While earlier studies mainly focused on interannual time scales, recent studies have highlighted the fact that on multidecadal time scales tropical-polar teleconnections also play an important role. Numerous tropical-polar teleconnections have been established, focusing on different tropical ocean basins. Ding et al. $(2011,2012)$ showed that the austral winter SAM anomalies are significantly correlated with SST changes in central tropical Pacific, while multidecadal Atlantic variability is also reported to drive West Antarctic climate change (Li et al. 2014; Simpkins et al. 2014). It is thus important to compare the mechanisms and dynamics behind different teleconnections, and to better identify the relative roles of these tropical ocean basins in driving West Antarctic climate change.

This study seeks to systematically assess the austral winter [June-August (JJA)] impact of SST changes across the tropical oceans using an atmospheric model, on multidecadal time scales. Model results suggest that while trends in all tropical basins have an impact, the Atlantic and western Pacific are the most significant: the Atlantic deepens the ASL, while the western Pacific generates a high pressure center west to the international date line. The effects of Indian Ocean warming and eastern Pacific cooling, both decreasing the pressure of ASL, are relatively weaker than those of the former two. Following $\mathrm{Li}$ et al. (2015), we interpret these responses as a consequence of Rossby wave propagation; using a primitive equation solver (Yoo et al. 2012) and Rossby wave tracing theory of Hoskins and Karoly (1981), we then estimate the total Rossby wavenumber (Ambrizzi et al. 1995) based on the climatological background state. Both the theoretical and the idealized model agree well with the realistic CAM4 simulation results, suggesting that the subtropical and midlatitude jets play a key role in channeling wave activity from the Atlantic and Pacific to West Antarctica.

The outline of this paper is as follows: The tropical SST trend is estimated in section 2, which is then used to force the atmospheric models. Results from the CAM4 comprehensive atmospheric model simulations are presented in section 3 , followed by results from the GFDL dry-dynamical core simulations in section 4, and those from the theoretical model in section 5. Conclusions are drawn in section 6.

\section{SST trend during the last three decades}

We use the Hadley Centre's Sea Ice and Sea Surface Temperature dataset (HadISST; Titchner and Rayner 2014.) to estimate the SST trend during the last three decades from 1979 to 2012, which serves as the external forcing of our numerical models. We also divide the tropical oceans into four sectors based on the observed trend.

There is a discontinuity in HadISST sea ice content (SIC) in 2009, due to the switching of satellite source data at that time. We have verified that this does not affect our linear regression results. The SST trend as well as its spatial-temporal variability retrieved from the HadISST dataset is further validated using the Kaplan extended SST data version 2 (Kaplan et al. 1998). The two datasets show consistent trends and variability, so the results from the Kaplan SST data are not shown in this paper.

During the last three decades, the tropical Pacific SST trend exhibits a dipole-type distribution. The eastern Pacific exhibits a mild cooling trend, with the basin-scale temperature changing by about $\sim 0.2 \mathrm{~K}$ (from 1979 to 2012; see Fig. 1). The western Pacific shows a warming trend of about $0.3 \mathrm{~K}$ (Fig. 1). In the tropical Atlantic Ocean, the average SST shows a stronger warming of about $\sim 0.5 \mathrm{~K}$. This warming trend is related to both global warming and the Atlantic multidecadal oscillation (AMO; Schlesinger and Ramankutty 1994; Knight et al. 2005). Over the Indian Ocean, the SST pattern shows a widely spread mild warming trend. The spatially averaged magnitude of the trend is less than $0.2 \mathrm{~K}$.

Based on the geographical ocean basins and the spatial distributions of the SST trends, we divide the tropical ocean into four sectors: the tropical Indian Ocean, 


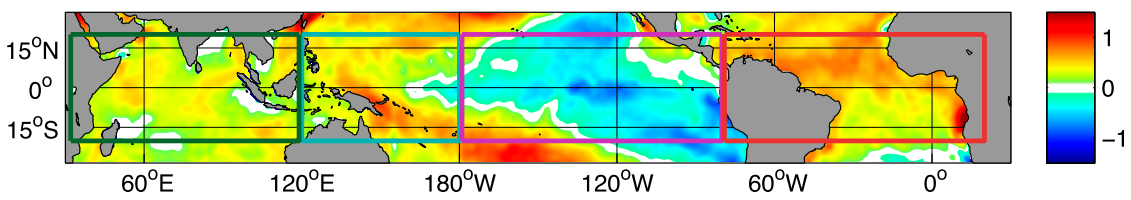

FIG. 1. Sea surface temperature (SST) trend and definition of tropical ocean sectors. The color mapping shows the SST trend from 1979 to 2012 . The unit of the SST trend is K (34 yr) ${ }^{-1}$. The boxes show the spatial definition of four different tropical ocean basins, with dark green box showing the tropical Indian Ocean, cyan box showing the west Pacific Ocean, purple box showing the east Pacific Ocean, and red box showing the tropical Atlantic Ocean. The west Pacific, Atlantic, and Indian Oceans exhibit warming trends during last 34 years, while the east Pacific shows a cooling trend. The SST trend in each ocean basin is used as external SST forcing in the CAM4 atmospheric model simulation.

western Pacific, eastern Pacific, and tropical Atlantic. The spatial definitions of these ocean sectors are illustrated in Fig. 1 by green, cyan, purple, and red boxes, respectively. We limit the northern and southern edges of these boxes over the tropical ocean to $20^{\circ} \mathrm{N}$ and $20^{\circ} \mathrm{S}$ respectively, with a $5^{\circ}$ linear buffer zone on each side (i.e., from $20^{\circ}$ to $25^{\circ}$ ). Considering that the impact of the teleconnections from different tropical ocean basins may potentially vary, we force our atmospheric models with the observed SST changes from these different ocean basins separately in order to single out their individual impact.

\section{CAM4 simulation forced by tropical SST trend}

We investigate the robustness and the linearity of the tropical-Antarctic teleconnections using the NCAR Community Atmosphere Model version 4 (CAM4; Gent et al. 2011). CAM4 is the atmospheric component of the Community Earth System Model (CESM). The horizontal resolution of the model we used is $\sim 2$ degrees. CAM4 is coupled to an active community land model (CLM), a thermodynamic sea ice model (CICE), and a data ocean model (DOCN). These modules help to estimate the lower boundary flux for the atmosphere model, ensuring that the only changes of the external forcing come from the lower boundary SST over the tropical ocean in DOCN.

We first quantify the Southern Hemisphere atmospheric responses to forcings from different tropical ocean sectors shown in Fig. 1. We then compare the model responses and reveal an interesting additive property of these teleconnections, namely that the impacts of different ocean sectors on the Southern Hemispheric atmospheric circulation are linear. By adding the simulation results forced by four individual ocean sectors, we derived a composite Southern Hemispheric response, which highly resembles the model results forced by the entire tropical ocean. In this simulation, we focus on austral winter, the season when the tropicalpolar teleconnections are reported to be the most robust and significant (Ding et al. 2011; Li et al. 2014, 2015).

\section{a. Sensitivity experiments}

To investigate the CAM4 response to each tropical ocean sector, we perform four pairs of sensitivity experiments. In each experiment, we compare the simulation results of a forced run with the control run. In the control run, the external SST forcing follows the climatological mean during the 1980s. All other climate forcings, including greenhouse gases and ozone concentration, as well as sea ice distribution, are set up based on the seasonally varying climatological mean of the same period. In the forced run, every external forcing remains the same except that an additional SST forcing representing the observed SST trend from 1979 to 2012 has been added to four different ocean sectors respectively: the tropical Indian, west Pacific, east $\mathrm{Pa}$ cific, and tropical Atlantic sectors (see again Fig. 1). Within these tropical ocean sectors, the surface temperature is fixed as the climatology plus the observed $34-y r$ trend. The difference in the simulation results between the forced and the control runs thus represents the model response to this additional SST forcing. Both the control and forced run were spun up for 10 model years and then run for another 100 years. This simulation period is sufficiently long to ensure that the results are robust and statistically significant.

The simulation results are shown in Fig. 2. Two strong model responses are found with respect to the tropical Atlantic warming (Fig. 2a) and the west Pacific warming (Fig. 2c). The tropical Atlantic warming induces a series of low pressure centers around the Antarctic continent, whose pattern is similar to an enhanced SAM. In particular, the tropical Atlantic warming deepens the SLP over the Amundsen Sea area, with SLP changes at about $2-3 \mathrm{hPa}$ (Fig. 2a). The west Pacific warming forms a Rossby wave propagating pattern from the subtropical 
A Trpoical Atlantic Forcing

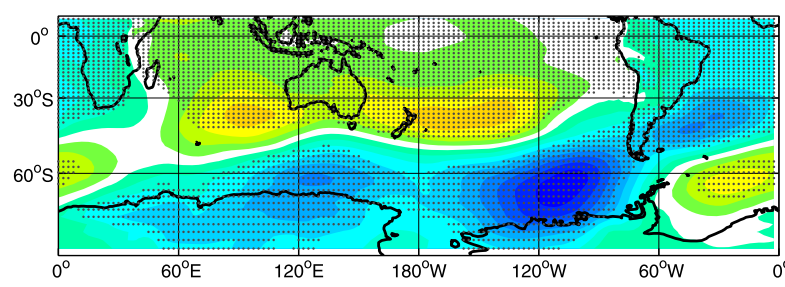

C Tropical Indian Ocean Forcing

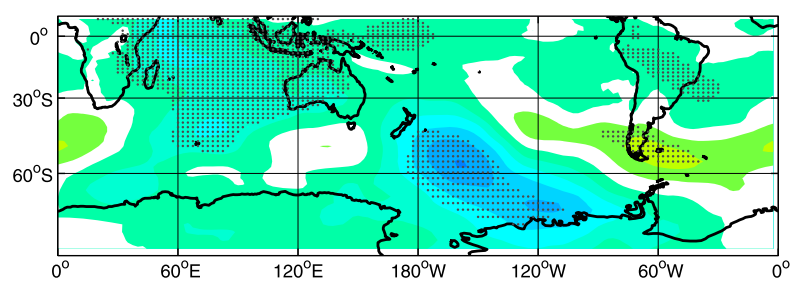

B West Pacific Forcing

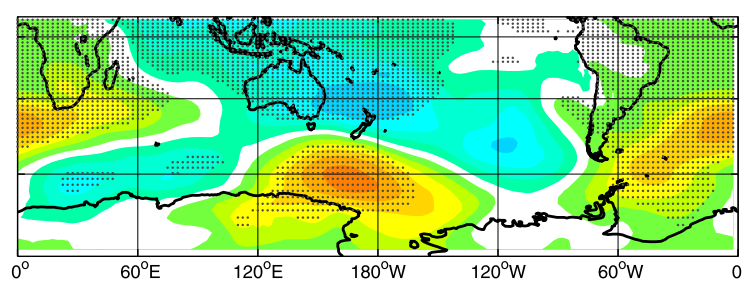

D East Pacific Forcing

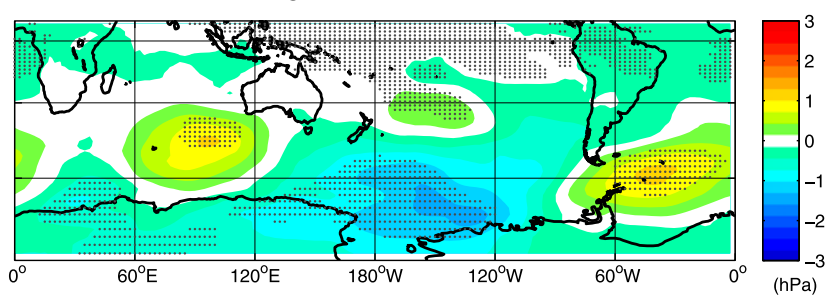

FIG. 2. CAM4 simulated sea level pressure (SLP) response to the sea surface temperature trend over four different ocean basins in austral winter. The unit of the SLP is Pascals (Pa). (a) The tropical Atlantic SST forcing simulation shows a strong cyclonic circulation anomaly over the Amundsen-Bellingshausen Seas low area, while (c) the west Pacific warming simulation shows strong positive SLP anomalies east of the Amundsen Sea. The (b) tropical Indian Ocean SST forcing and (d) east Pacific SST cooling simulations both induce weak cyclonic circulation anomalies over the Amundsen Sea low area. The area above $95 \%$ confidence interval is marked with gray dots.

Indo-western Pacific to the southeastern Pacific. It strongly increases the SLP over the Ross Sea (Fig. 2c). The model responses to the warmed Indian Ocean and cooled eastern Pacific are comparatively weaker, both of which deepen the ASL in the CAM4 simulation. In all simulations forced by the Atlantic and Pacific SST changes, we can observe distinct wave features, implying an underlying Rossby wave dynamics, which is consistent with previous understanding of tropical-polar teleconnections (Hoskins and Karoly 1981; Hoskins and Ambrizzi 1993; Jin and Hoskins 1995; Ding et al. 2011; Li et al. 2015).

Through the above sensitivity experiments, the roles of various ocean sectors are explicitly revealed: tropical Atlantic warming, Indian Ocean warming, and east $\mathrm{Pa}-$ cific cooling decrease the pressure over the Amundsen Sea area, whereas west Pacific warming increases the SLP over the western part of the Ross Sea. The impacts of the tropical Atlantic and west Pacific are stronger than those of the other two sectors, partly due to the stronger SST trends over these two regions. The simulated atmospheric circulation response is barotropic, as the model response at the 200-hPa geopotential height $(\mathrm{GPH})$ indicates a similar pattern to the SLP changes (figure not shown).

\section{b. Linearity between different ocean sectors}

In the above experiments, the tropical oceans are divided into various sectors and analyzed individually. The comparison between different ocean basins is based on an assumption that the relationship between different teleconnections is linear, and in this linear (or weakly nonlinear) system the model response to the entire tropical SST forcing is approximately equal to the accumulation of the model responses to each individual ocean sector. Here we further validate this assumption.

We conduct a sensitivity experiment forced by the entire tropical SST warming. The model response of the SLP is shown in Fig. 3a. The SAM is enhanced, characterized by a lower pressure over Antarctica and a mild positive SLP anomaly around the subtropical jet. The ASL is dramatically deepened, associated with a cyclonic circulation anomaly around this area.

We then combine the four simulations in section $3 \mathrm{a}$ to a cumulative model response to these tropical ocean SST changes, as shown in Fig. 3b. This cumulative result shows a strong similarity to the entire tropical forcing result (Fig. 3a). In particular, the spatial pattern correlation (of SLP) between the two simulation results is 0.88 (in this spatial pattern correlation, only the region south to $30^{\circ} \mathrm{S}$ is taken into account, and each grid point is weighted by its area). To further estimate the linearity of the atmospheric circulation changes to the north of West Antarctica, we calculate the spatial mean SLP anomalies over the rectangular area shown in Fig. $3 \mathrm{~b}\left(60^{\circ}-75^{\circ} \mathrm{S}\right.$, $\left.90^{\circ}-150^{\circ} \mathrm{W}\right)$. The SLP decreases by $\sim 357 \mathrm{~Pa}$ in the entire tropical SST warming simulation (Fig. 3a), while the cumulative result (Fig. 3b) indicates a comparable reduction of $\sim 349 \mathrm{~Pa}$. This strong coherency indicates a highly linear dynamics, further implying that Rossby 


\section{A. Global Tropical SST Forcing}

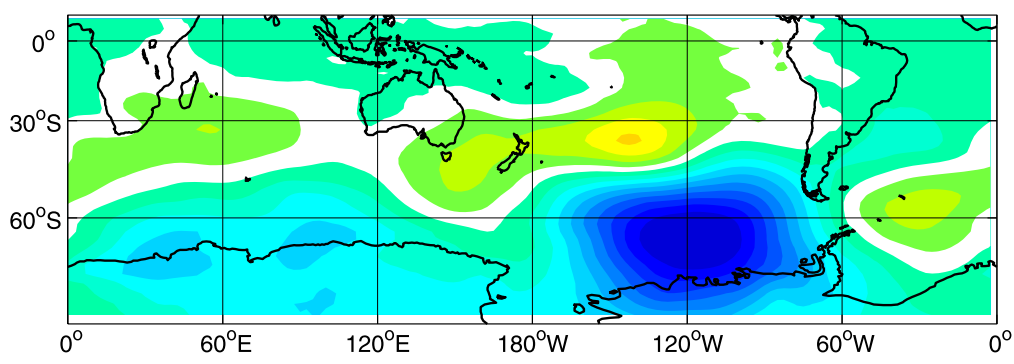

\section{B. Combination of For Tropical Forcing}

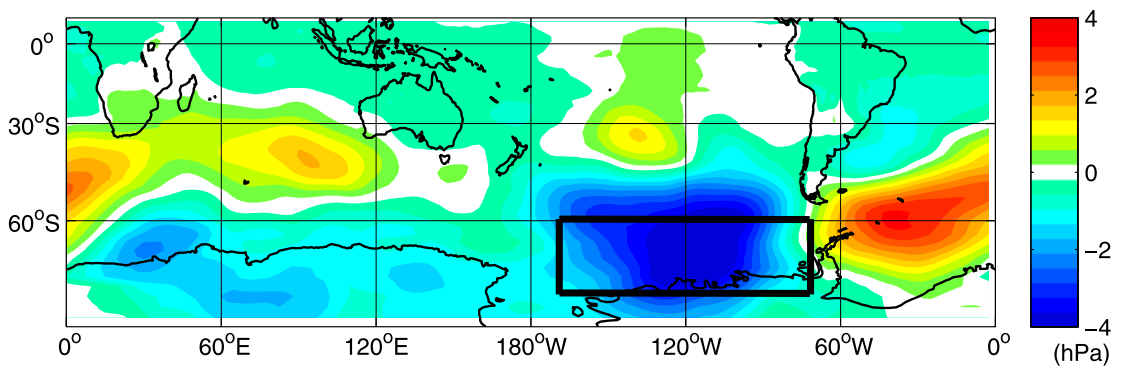

FIG. 3. Linearity of the model response with respect to different forcing regions. The unit is hPa. (a) The JJA CAM4 simulated SLP response to the entire tropical SST trend. (b) The summation of responses to surface SST forcing from the tropical Atlantic, tropical Indian Ocean, west Pacific, and east Pacific. The similarity between (a) and (b) indicates that the model response to the SST forcing from different tropical sectors is linear.

wave dynamics may dominate the teleconnection. Another interesting feature of this additive property is that the SLP from these two simulations shows the strongest coherence around the ASL area, but there is less coherence farther east. One possible explanation is that the Rossby wave rays from different ocean basins intersect with each other over the ASL region.

\section{GFDL simulation of Rossby wave trains}

As a comprehensive atmospheric model, the CAM4 simulations involve numerous physical processes, many of which are parameterized. While these processes enable a more realistic simulation result, they also complicate the isolation of pure Rossby wave dynamics. To further investigate the underlying physical mechanism and the dynamical evolution of these teleconnections, we employ the spectral dry-dynamical-core of an atmospheric general circulation model (Held and Suarez 1994) developed at the Geophysical Fluid Dynamics Laboratory (GFDL). The GFDL dry-dynamical-core serves as a numerical solver of the primitive equations. It is set up with a horizontal resolution of $\sim 3$ degrees (T42). The model is initialized with a climatological background flow averaged from the interim European Centre for Medium-Range Weather Forecasts (ECMWF) interim reanalysis (ERA-Interim; Dee et al. 2011) for the JJA austral winter season, from 1979 to 2012.

At each time step, an additional forcing is added to the primitive equations, in order to balance the climatological forcing (James et al. 1994; Yoo et al. 2012) and to stabilize the model. This additional forcing is obtained by integrating the model one time step forward from the initial condition, which neutralizes the model's initial tendency. Without external perturbation, this additional forcing ensures that the model remains in its climatological state. We then add an initial perturbation over the tropical oceans. The model results at each snapshot can be considered as the evolution of the primitive equation dynamics in response to the additional initial forcing [see Yoo et al. (2012) for details].

We present four idealized simulation results, whose initial perturbations are illustrated in Fig. 4. The four idealized forcings correspond to the four ocean sectors in the CAM4 model: tropical Atlantic warming (Fig. 5a), tropical Indian warming (Fig. 5b), west Pacific warming (Fig. 5c), and east Pacific cooling (Fig. 5d). To validate the robustness of the idealized simulation results, we conducted several other experiments by changing the location of the initial forcing slightly south or north to the equator. However, the results show that the Rossby wave trains are not sensitive to the exact latitude of the 


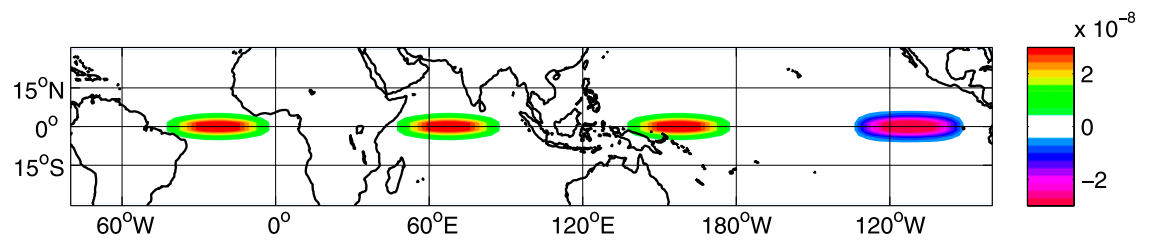

FIG. 4. Horizontal structure of the idealized forcing in the GFDL dry-dynamical-core simulations. The color mapping shows the idealized forcing of the (left to right) tropical Indian Ocean, west Pacific, east Pacific, and Atlantic forcing. This external forcing represents the convective heating forced by regional SST warming.

initial heating, as long as it is located within the tropical region (results not shown).

According to the idealized simulation results, the convective heating/cooling from all four areas immediately generates a deep convection disturbance, exciting a poleward propagating Rossby wave train, further confirming that Rossby wave dynamics dominate the mechanism of tropical-polar teleconnections.

More specifically, the Rossby wave trains (Fig. 5a) generated by the tropical Atlantic warming first propagate to the south, and then to the east. These wave trains are guided by the subtropical jet, propagating around the globe within two weeks. They finally arrive at the Amundsen Sea area and deepen the regional (local) low pressure center. The wave packets form a similar pattern as shown in the CAM4 simulation (Fig. 2a), with a strong low pressure center over the ASL area, and a secondary low pressure center around $90^{\circ} \mathrm{E}$, near Mirny station. There are also some differences between the GFDL and CAM4 simulations. The ASL low pressure center simulated by GFDL model [Fig. $5 \mathrm{a}(3)$ ] is about $20^{\circ}$ west to that in CAM4 [plus symbol in Fig. 5a(3)]. Additionally, the CAM4 results appear smoother than the GFDL simulated wave trains. This is because the GFDL is a dry-dynamical model, representing pure Rossby wave dynamics. In contrast, CAM4 involves many additional physical processes, in particular the moist-physical processes.

The convective heating from the Indian Ocean (Fig. 5b) also generates a Rossby wave train from the subtropical western Indian Ocean to the Antarctic Peninsula. The wave trains propagate poleward and then eastward, inducing a low pressure center around the western Amundsen Sea. The CAM4 result is comparatively weaker due to the weak SST trend in the Indian basin. In addition, the ASL low pressure center in CAM4 simulation is to the northwest of that in the GFDL model.

The Rossby wave trains generated by the western Pacific warming (Fig. 5c) do not originate solely from the Pacific basin; rather, the majority of Rossby wave packets originate in the eastern Indian Ocean. This wave train propagates poleward and finally induces a high pressure center from the Ross Sea to the western Amundsen Sea. The high-low-high wave packets resemble the wave propagating pattern in CAM4 simulation (Fig. 3c, forced by the western Pacific warming). However, the wave trains simulated by the CAM4 model undergo a westward shift. The high pressure center in CAM4 is almost $40^{\circ}$ west of that in the GFDL results, a large difference. Further analysis shows that the strong Southern Hemisphere subtropical/midlatitude jet plays an important role in the wave propagation. Small changes of the location and intensity of the jet may also impact on the simulation result of the Pacificinduced Rossby wave trains.

The eastern Pacific cooling also generates Rossby wave trains, from the eastern Pacific to Antarctica, forming a low pressure anomaly center from the Amundsen Sea to the Drake Passage and the South Atlantic. This low pressure center [Fig. $5 \mathrm{~d}(3)$ ] is about $40^{\circ}-50^{\circ}$ east to the center in the CAM4 simulation [Fig. 2d, the plus symbol in Fig. 5d(3)]. In addition, the low pressure center in CAM4 is much weaker than that in GFDL simulation. Lachlan-Cope and Connolley (2006) indicate that the eastern Pacific is a region of climatological descent because of the comparatively low SST. The ocean temperature perturbation can hardly generate deep convections in that region. The eastern Pacific cooling anomaly may only be able to alter the large-scale atmospheric circulation through the temperature gradient. The Rossby wave source (RWS) triggered by the eastern Pacific cooling is much weaker than that from other tropical forcing. This may explain why the impact of the eastern Pacific cooling is weaker in CAM4 simulation.

Finally, we compare the amplitudes of the model responses over West Antarctica across these four simulations. Recall that the amplitudes of each initial perturbation are identical. The intensities of the model responses thus only depend on the Rossby wave formation and propagation, which is further related to the zonal asymmetry of the background flow. We find that initial forcing over the western Pacific generates the strongest model response west to the Amundsen Sea 
A1 : Tropical Atlantic day3

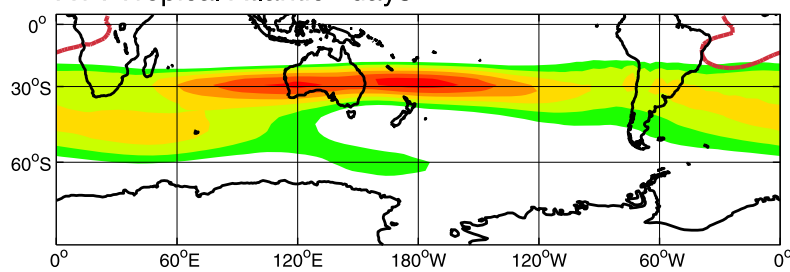

A2: Tropical Atlantic day9

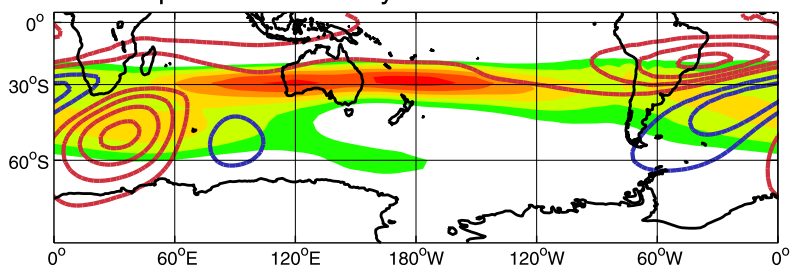

A3: Tropical Atlantic day18

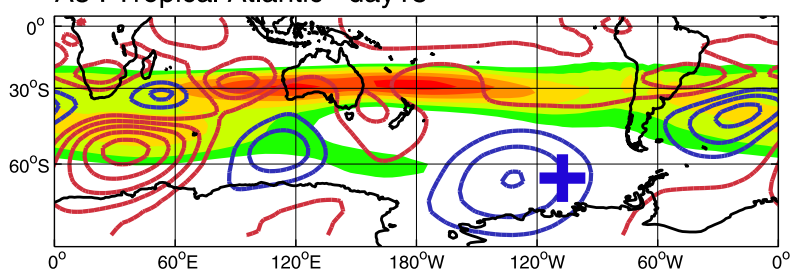

C1: West Pacific day3

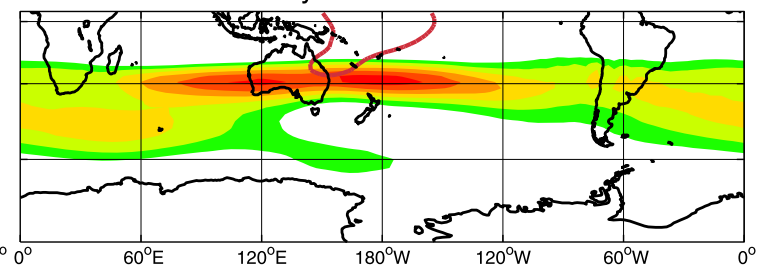

C2 : West Pacific day9

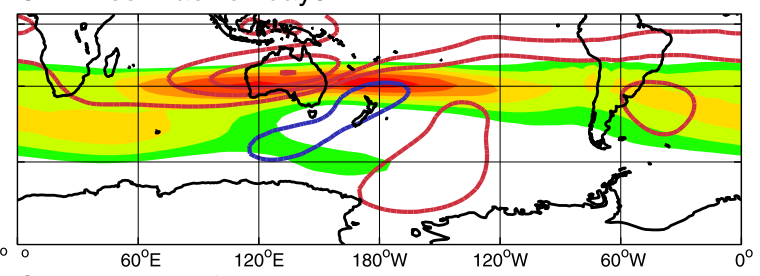

C3 : West Pacific day18

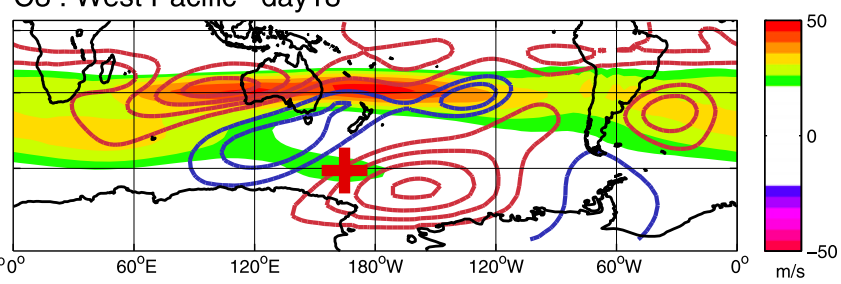

B1 : Indian Ocean day3

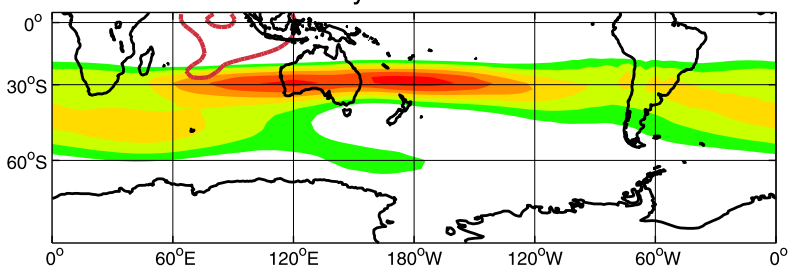

B2 : Indian Ocean day9

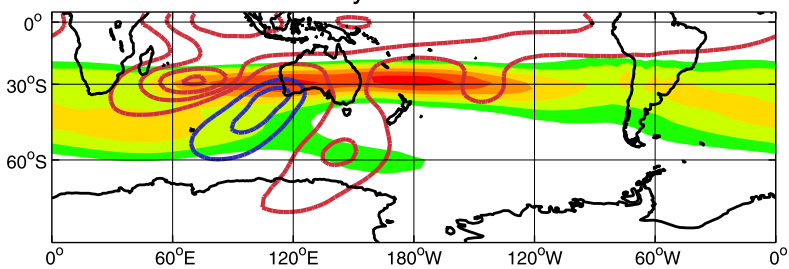

B3 : Indian Ocean day18

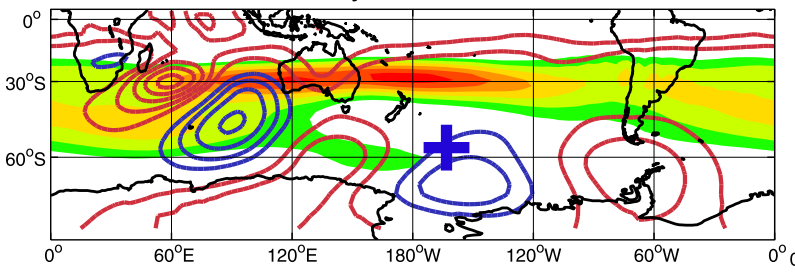

D1 : East Pacific day3

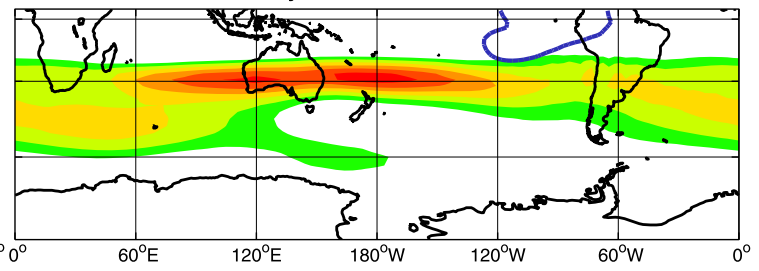

D2 : East Pacific day9

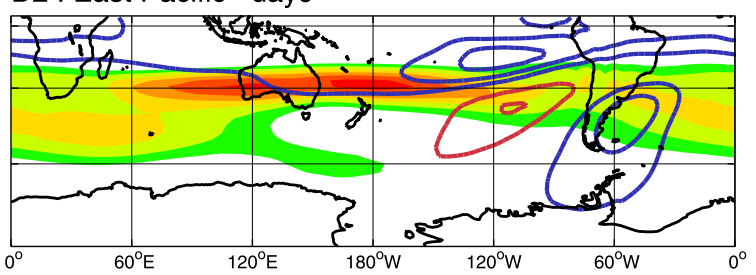

D3 : East Pacific day18

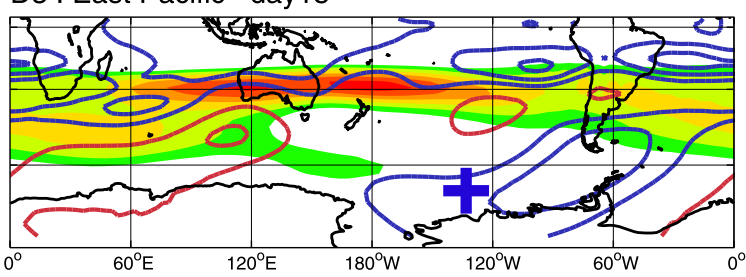

FIG. 5. GFDL idealized simulations with initial forcing from the tropical ocean basins. The contours show the simulated 200-hPa geopotential height with contour interval of $10 \mathrm{~m}$, while the color shading shows the imposed climatological mean 200-hPa zonal wind. The unit is $\mathrm{m} \mathrm{s}^{-1}$. (a1)-(a3) Results with initial forcing from the tropical Atlantic Ocean, with three model snapshots from day 3 to day 18 . The other panels are as in (a1)-(a3), but for initial forcing from the (b1)-(b3) tropical Indian Ocean, (c1)-(c3) west Pacific Ocean, and (d1)(d3) east Pacific Ocean. All simulations are forced by the background flow of June-August (JJA). The low (high) pressure centers in the CAM4 simulations are marked with blue (red) plus signs. 


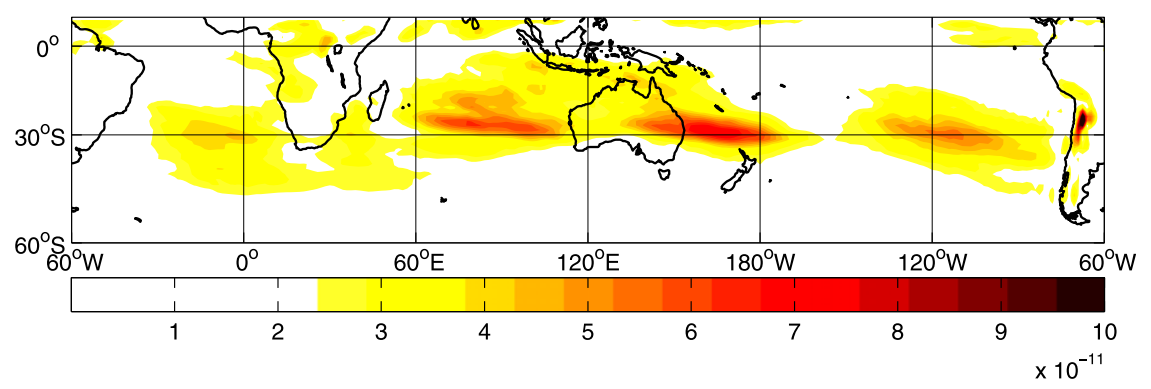

FIG. 6. The standard deviation of 200-hPa Rossby wave source (RWS) over tropical oceans in JJA. The unit of the color shading is $1 \mathrm{~s}^{-1}$.

area, which is about $4 / 3$ times and opposite that of the tropical Atlantic or eastern Pacific simulation. Model responses to the tropical Indian Ocean are the weakest. Moreover, considering that the SST warming trend over the tropical Atlantic region is stronger than that over the other ocean basins, it is thus reasonable that the tropical Atlantic SST trend also induces a strong response in the CAM4 simulation.

It is important to point out that the GFDL model has a dry-dynamical core and is based on the preliminary equation dynamics and the background field of GFDL model is smoother, so the results are comparatively unrealistic compared to the comprehensive CAM4 model. As a comprehensive atmospheric model, the CAM4 simulations involve numerous physical parameterization processes. While the CAM4 simulations are used to quantitatively estimate the impact of the tropical warming, the GFDL dry-dynamical core experiments provide us with qualitatively similar results, showing a clear Rossby wave dynamics linking the tropical ocean and polar atmospheric circulation.

\section{Theoretical Rossby wave models}

According to the above simulations using two numerical models, the tropical-Antarctic teleconnections are pronounced in all ocean tropical basins, although the amplitude of the forcing and the response vary. On multidecadal time scales, this difference can be related to the intensity of the initial forcing (i.e., the different observed SST trends over the four tropical ocean basins). In addition to this change in SST forcing, the divergence of the wave amplitudes may also be influenced by Rossby wave dynamics themselves, which depends critically on the background flow over the source region, as well as along the path of the wave trains.

To further study the dynamics of these Rossby wave trains, we introduce a theoretical Rossby wave model, the Hoskins-Karoly model (Hoskins and Karoly 1981; Sardeshmukh and Hoskins 1988). We calculate the
RWS from different tropical ocean basins and then integrate the stationary Rossby wave trajectories from these areas. Both the RWS and trajectory calculation are based on the ERA-Interim reanalysis dataset. The theoretical model results agree well with the comprehensive and idealized atmospheric models, showing that the background flow, especially the subtropical/ midlatitude jet, plays an important role in the tropicalpolar teleconnections.

\section{a. Rossby wave sources}

We estimate the activity of the RWS over the tropical/ subtropical region (Fig. 6). Over the tropical ocean, SST changes generate deep atmospheric convection, driving anomalous divergence in the subtropical upper troposphere, and perturbing the subtropical circulations. The source and activity of Rossby wave trains can be considered as a function of absolute vorticity and divergence of the upper-troposphere background flow (Sardeshmukh and Hoskins 1988), given by

$$
S=-\nabla \cdot\left(\zeta \nu_{\chi}\right)
$$

Here $S$ is the Rossby wave source, $\zeta$ is the absolute vorticity, and $\nu_{\chi}$ indicates the divergent component of the horizontal velocity. An active RWS requires both strong shearing and divergent flow. Over the subtropical area, the downwelling branch of the Hadley cell forms the convergent flow, while the strong shear appears around the subtropical/midlatitude jets.

The variability (monthly standard deviation) of the RWS is shown in Fig. 6, whose distribution indicates similar spatial patterns for all four seasons, and is highly related to the zonal structure of the atmospheric jet system over the Southern Hemisphere (see background color shading in Fig. 5). Here we show austral winter (JJA) RWS variability, when the tropical-Antarctic teleconnection is observed to be the most significant. The strongest RWS is always located over the subtropical Indian and western Pacific Oceans, around $20^{\circ}-40^{\circ} \mathrm{S}$. 
Indeed, this is the area where the subtropical jet reaches its peak (Fig. 5). The strong jet structure provides a strong background vorticity, perturbed by the downwelling flow of the Hadley cell, forming the strongest RWS area.

In contrast, the RWS over the Atlantic and eastern Pacific is much weaker, and extends farther south until $45^{\circ} \mathrm{S}$, which is partly caused by the weakened zonal structure over the midlatitude jet area (Fig. 5). In particular, over the Atlantic Ocean, the intensity of the RWS is just about one-third of that over the subtropical Indian and western Pacific Oceans. This contrast raises a question, namely why the weaker RWSs over the subtropical Atlantic generates Rossby wave trains as strong as the subtropical western Pacific. We further investigate this paradox by integrating the Rossby wave trajectories from different subtropical ocean basins, according to the Hoskins-Karoly stationary Rossby wave model.

\section{b. Ray tracing}

We simplify the primitive equation dynamics, and recall the linearized Rossby wave dispersion relationship:

$$
\omega=U k-\frac{\beta^{*} k}{K^{2}},
$$

where $\omega$ is the frequency of the Rossby waves, $U$ is the zonal velocity of the background flow, $k$ is the zonal wavenumber, $K=\sqrt{k^{2}+l^{2}}$ is the total wavenumber, $l$ is the meridional wavenumber, and $\beta^{*}=\beta-U_{y y}$ is the meridional gradient of the absolute vorticity. For stationary Rossby waves, the phase velocity $\omega$ equals to zero, and we thus have

$$
U k=\frac{\beta^{*} k}{K^{2}} .
$$

We further calculate the total wavenumber based on the background state (Ambrizzi et al. 1995)

$$
K=\sqrt{\frac{\beta^{*}}{U}}=\sqrt{\frac{\beta-U_{y y}}{U}}
$$

and further derive the group velocity of a stationary Rossby wave as follows:

$$
\begin{aligned}
& c_{g x}=\frac{\partial \omega}{\partial k}=\frac{2 \beta^{*} k^{2}}{K^{2}}, \\
& c_{g y}=\frac{\partial \omega}{\partial l}=\frac{2 \beta^{*} k l}{K^{2}} .
\end{aligned}
$$

Dividing these two equations, we have the direction of the wave front at each location:

$$
\frac{d x}{d y}=\frac{c_{g x}}{c_{g y}}=\frac{k}{l},
$$

which is a function of latitude and zonal velocity in the background flow. By integrating this function along the wave path, we can obtain the trajectory of the stationary Rossby waves.

Considering that the horizontal scale of a Rossby wave packet is always $\sim 1000 \mathrm{~km}$ or more, while the zonal structure of the subtropical/midlatitude jet may significantly vary within a Rossby wave packet, we first smooth the background state with respect to the specific Rossby wavelength. In addition, instead of a deterministic integration, we slightly perturb the starting point as well as the background state in order to obtain an ensemble integration of these Rossby wave trajectories.

We start the Rossby wave ray tracing from the subtropical area from $20^{\circ}$ to $40^{\circ} \mathrm{S}$ over different ocean basins, which is indicated above as the RWS area. The Rossby wave trajectories derived from the ray-tracing model are shown in Fig. 7, which indicates several wave paths from the tropical oceans to the Antarctic region. In addition, the strong shear around the jet structure may reflect and confine the wave trains, directing them either to the tropical or the polar region.

The wave trains from the tropical Atlantic Ocean (Fig. 7a) first propagate to the south. These wave trains are then reflected and guided by the subtropical jet $(\mathrm{Li}$ et al. 2015) and finally concentrate on the West Antarctica area. Most of the wave trains starting from the Atlantic Ocean finally arrive at the South Pole region. The cluster of these wave trajectories agrees well with the wave structures shown in the CAM4 and GFDL simulations. The coherency between comprehensive, idealized, and theoretical models further strengthens the conclusion that Rossby wave dynamics link Antarctic climate variability to the tropical Atlantic SST changes.

In contrast to those from Atlantic Ocean, the wave trains from other basins are weakened by the subtropical jet. The jet reflects some of the trajectories back to the trade wind area. As an example, Fig. $7 \mathrm{~b}$ shows the wave trains from the western Indian Ocean. Most of the trajectories north to $30^{\circ} \mathrm{S}$ are reflected by the southern edge of the subtropical jet, and terminate along the critical line.

The wave trains from the western Pacific show more complicated propagation patterns. The trajectories west to Australia (Fig. 7c) show similar features to that from western Indian Ocean: wave trains south of subtropical jet can propagate to the polar region, while those north of subtropical jet are reflected back to the critical line. The trajectories east to Australia (Fig. 7d), however, are all reflected back to the tropical area. Further analyses reveal that the zonal wind shear reaches its peak in the area between subtropical and subpolar jet, making it too strong for stationary waves to pass. This intense shear 

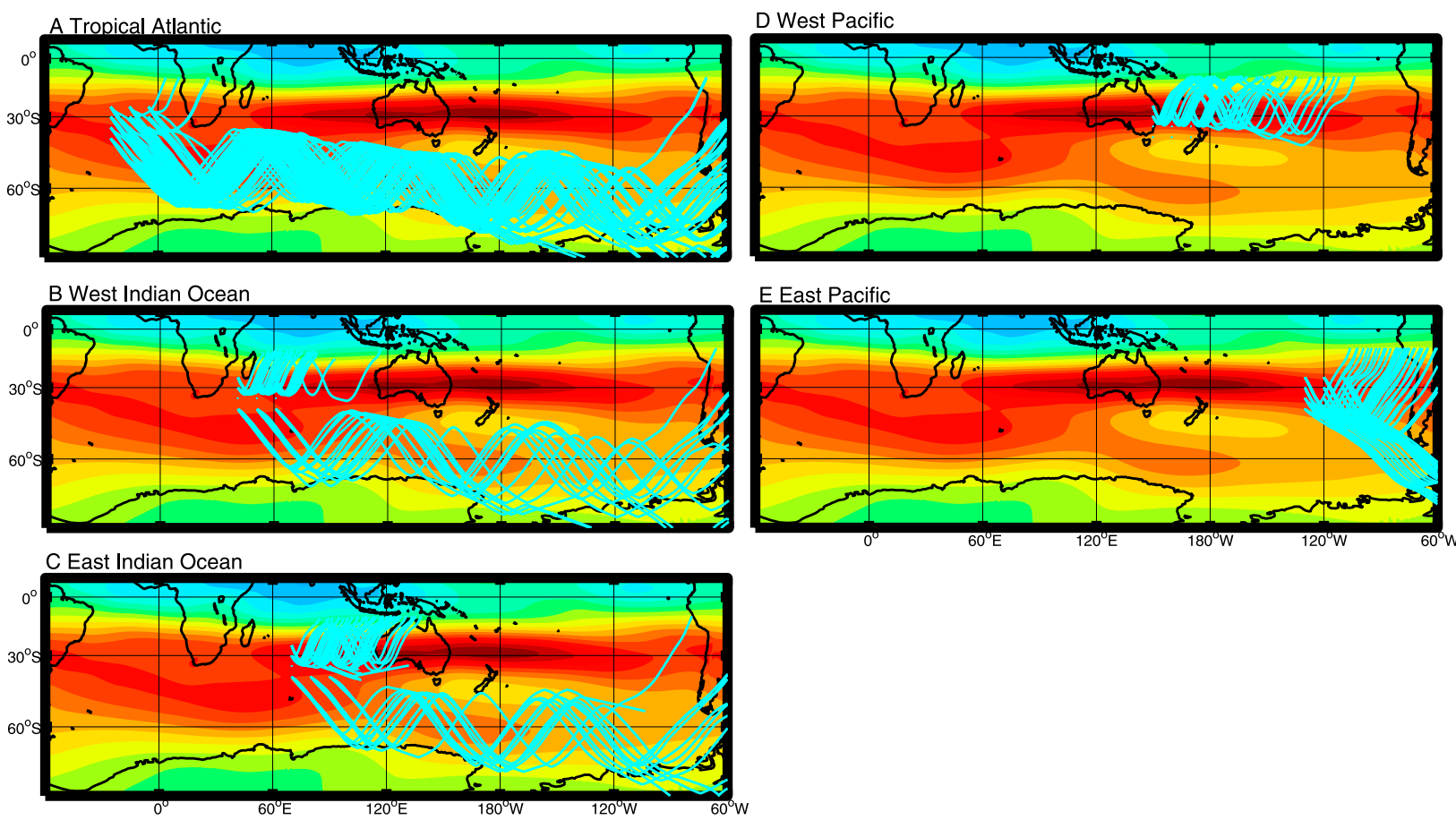

FIG. 7. Stationary Rossby wave trajectories with zonal wavenumber $k=2$. These trajectories are from the (a) tropical Atlantic, (b) western Indian Ocean, (c) eastern Indian Ocean, (d) western Pacific, and (e) eastern Pacific. The background color shows the 200-hPa zonal wind. In each experiment, we initiate the wave trajectories from different locations within a small area. We also perturb the climatological background flow by changing the averaging time period, in order to obtain an ensemble of wave rays traced from each ocean basin.

flow blocks the wave trains that start from the east of the Australian continent. The jet structure finally weakens the Rossby wave trains from the subtropical Indowestern Pacific area. Figure 7e shows the wave trains starting from the subtropical eastern Pacific. Most of the wave trains propagate to the West Antarctica region.

These theoretical model results show similar Rossby wave pathways to that in the comprehensive and idealized atmospheric models, and provide a physical explanation as to why the weak RWS over the subtropical Atlantic Ocean may generate a Rossby wave train as strong as that from the western Pacific. It also helps to reveal the mechanism of why the Rossby wave trains forced by the western Pacific warming start from the eastern Indian Ocean [Figs. $2 c$ and $5 c(3)$ ] instead of the high RWS area east to Australia continent (Fig. 6). According to the complicated dynamics around the jet area, the theoretical Rossby wave trajectory model provides qualitative but not quantitative explanation. However, by involving more comprehensive physical dynamics, the CAM4 and GFDL provide a more quantitative estimation of the impacts from different ocean basins.

Ambrizzi et al. (1995) showed that the stationary Rossby wavenumber can be used to study the wave propagation as well as the teleconnection patterns, since it indicates the largest wavenumber that can be propagated in a particular region. To further investigate the physical dynamics of these Rossby wave trajectories, we decomposed each term of the theoretical model as follows: the total wavenumber $K$ can be considered as a function of the latitude and the background flow. We illustrate the total wavenumber together with the meridional gradient of the absolute vorticity in Fig. 8 . During austral winter, the subtropical jet is strong, and the subpolar jet is separated from the subtropical jet. The difference in the magnitude of $U_{y y}$ between the subtropical and subpolar jet is large, which dramatically reduces the meridional gradient of the absolute vorticity, shown in Fig. 8b as the deep blue area to the east of Australia. As a result, the total wavenumber $K$ becomes an imaginary number, and the waves can no longer propagate. This strong zonal wind shear $\left(U_{y y}\right)$ acts like a double-sided mirror (shown as the white areas in Fig. 8a) and reflects the wave trains back to the tropical regions.

The subtropical jet simulated by the CAM4 model is slightly stronger (figure not shown) compared to that in the ERA-Interim reanalysis data. In particular, the simulated zonal wind over the Indo-western Pacific area is much stronger than that in the reanalysis data. Based 

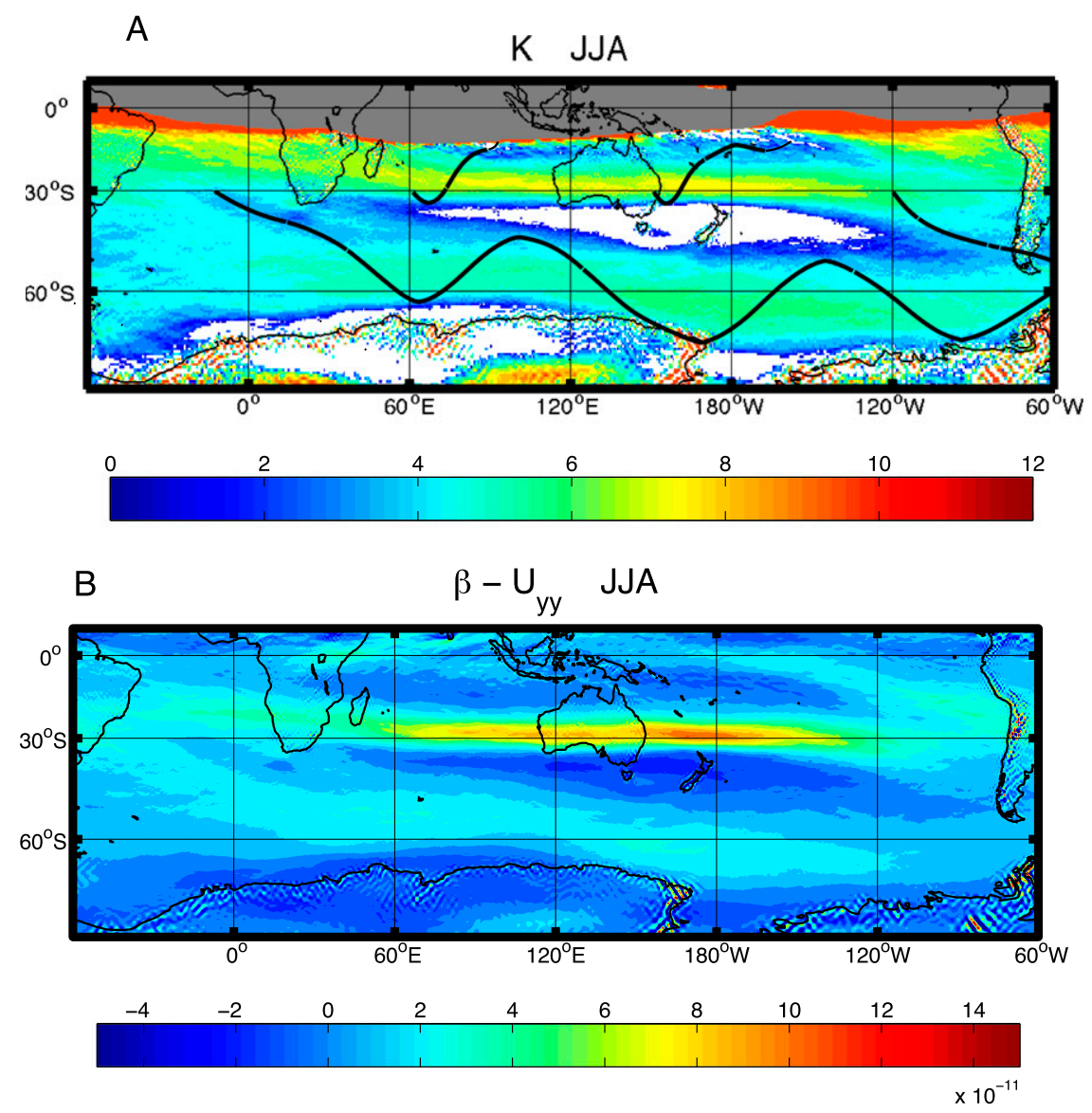

FIG. 8. The total wavenumber of the stationary wave and the meridional gradient of the absolute vorticity. (a) The total wavenumber of the stationary wave. The white area shows regions with imaginary wavenumbers, caused by negative values of the meridional gradient of the vorticity. The gray area shows the region with imaginary wavenumbers due to the easterly trade winds. The black curves show trajectories from the four RWS areas, to better illustrate the "reflection" of these trajectories. (b) The meridional gradient of the absolute vorticity in the climatological background field. The unit is $1 \mathrm{~m}^{-1}$.

on the above theoretical model, the stationary Rossby waves cannot propagate through the subtropical jet when the zonal wind speed is too large. The waves from the western Pacific are blocked by the "enhanced" subtropical jet in the CAM simulation, and thus can no longer pass the Indo-western Pacific area. As a result, the wave trains instead propagate through the Indian Ocean, undergoing a westward shift compared to the GFDL simulation. In addition, the initial perturbation in the GFDL dry-dynamical core is idealized, whereas in CAM4 it is forced by the observed SST trend. In this study, the CAM4 simulations provide a quantitative analysis of the impacts of the SST changes from different ocean basins, while the GFDL dry-dynamical core qualitatively shows that each of these tropical-polar teleconnections is dominated by the stationary Rossby wave model. Both simulation results agree with the diagnostic results based on the theoretical Rossby wave ray-tracing model.

The Rossby wave ray-tracing model is a highly linearized theoretical model, which simplifies the Rossby wave dynamics in the real atmosphere. This theoretical model leads to a conclusion consistent with that reached by the comprehensive and idealized atmospheric models. This strong coherence helps us to better understand how tropical SST changes impact on the Southern Hemisphere atmospheric circulation. In particular, all three of these models show that the subtropical jet plays an important role in tropical-polar teleconnections. The wind shear around the subtropical Indo-western Pacific basins forms strong vorticity, which helps generate a strong RWS. However, this wind shear may also reflect the stationary wave trajectories, thus weakening the wave trains from the tropical to the polar 
region. The strong subtropical jet around Australia plays contradictory roles, enhancing the RWS nearby yet weakening the local Rossby wave path, especially to the north of the jet.

\section{Conclusions and discussion}

In this study, we investigate the impacts of different tropical ocean sectors on Southern Hemisphere atmospheric circulations, using a comprehensive model (CAM4), an idealized model (GFDL dry-dynamical core), and a theoretical Rossby wave model (HoskinsKaroly). We divide the tropical oceans into the tropical Atlantic, tropical Indian, western Pacific, and eastern Pacific, according to the geographical ocean basins and the SST trends during the last three decades.

The CAM4 simulations reveal a linear property among different tropical-polar teleconnections, namely that the impacts of the entire tropical ocean on polar climate are similar to the summation of tropical-polar teleconnection from individual ocean basins. The four tropical ocean regions work together with each other and alter the circulations around West Antarctica. This linear property is only observed for austral winter in the CAM4 simulation. The result agrees well with Simpkins et al. (2014). In their study the impacts of different ocean sectors are found to be nonlinear for austral spring. A possible reason for the nonlinearity during these two seasons is that the background flow during the transient seasons is less stable than that for austral winter. According to our study, the variability of the background flow may impact on both the RWS formation and the Rossby wave propagation.

Based on this wintertime additive property, we can divide the tropical ocean into different sectors and study their impact individually. We show that the teleconnections from the tropical Atlantic and from the western Pacific are the most pronounced, while the impacts from the Indian Ocean and the eastern Pacific are comparatively weaker. The multidecadal SST changes from the tropical Atlantic, the Indian, and the eastern Pacific Oceans induce a lower pressure anomaly over the oceans off the Western Antarctic coast, while the western Pacific warming induces a higher pressure center over the Ross Sea. These simulation results agree well with previous observation-based studies (Ding et al. 2011, Li et al. 2014), showing that the central-west Pacific warming and the Atlantic warming result in the strongest response in the Southern Hemisphere atmosphere.

We reproduce our CAM4 results in a relatively idealized atmospheric model, the GFDL dry dynamical core, to further study the dynamical evolution of these teleconnections. Forced by the observed background flow, the GFDL model showed the evolutions of these Rossby wave trains originating from different ocean basins. These experiments further confirmed the robustness of each teleconnection, as well as clarified their mechanisms, which are shown to critically depend on the Rossby wave dynamics. Finally we used the HoskinsKaroly theoretical model to investigate the physical dynamics of these Rossby wave trains. Combining the results from all three models, our study shows that the subtropical jet plays a vital role in tropical-polar teleconnections. The jet structure may either enhance the RWS over the subtropical region or reflect the Rossby wave trajectories to either the tropical or the polar regions. This mechanism dramatically changes the intensity of Rossby wave trains from these four tropical ocean sectors. In particular, although the wind shear around the Atlantic is comparatively weak, which weakens the RWS over this region, the wave trains from Atlantic are well guided by the subtropical jet to the polar region, forming a robust link. On the other hand, the subtropical jet around the Indo-western Pacific is strong, and thus forms strong RWSs. However, the majority of the Rossby wave trains are reflected back to the tropics by the strong jet structures, which weakens the relationship between the Indo-western Pacific and the Southern Hemisphere circulation. In addition, previous work (Renwick and Revell 1999) showed that the western Pacific is more prominent in terms of Rossby wave propagation in spring compared to the other seasons. One possible reason is that the subtropical jet during that season is weak enough to allow Rossby wave packets to pass but still provide a strong enough potential vorticity gradient to generate the RWS.

The results of our models show strong coherence, indicating that our conclusions capture the main features of these tropical-polar teleconnections. The results also show that these teleconnections depend critically on the background flow, especially the subtropical jet, the midlatitude jet, and the subpolar jets. Looking forward, to better simulate these teleconnections, we need to improve the simulation skill of the jet structures in the dynamical models. In addition, understanding the teleconnection during the other seasons also require model studies, although the teleconnections for the transient seasons (spring and autumn) may involve even more complicated dynamics. Finally, air-ice-sea interactions are not included in our study, yet they may play an important role in these teleconnections. This will be the subjects of future study.

In austral winter, the SLP trend over ASL area is insignificant in reanalysis datasets. In contrast, its internal variability is strong. We estimated the SLP trend using ERA-Interim dataset and found it to be $0.1 \pm 5.5 \mathrm{hPa}$ 
from 1979 to 2012. In austral spring, however, the ASL is deepened in almost all reanalysis product (Clem and Fogt 2015). The uncertainties of the SLP trend in austral winter come from the reanalysis datasets themselves, since there are no systematic in situ SLP observations over the ASL area and, unlike the sea ice concentration or sea surface height, the SLP cannot be observed remotely by satellites. As a result, the SLP trend highly depends on the model used in the reanalysis system. Our simulation results emphasize the mechanisms and the complexity of the ASL anomaly, thus highlighting the need for direct SLP measurements in the ASL area.

Acknowledgments. We thank the three anonymous reviewers for their insightful comments on earlier versions of the manuscript, which dramatically improve the quality of this paper. X.L. was supported by the New York University Abu Dhabi G1204, and the Scripps Postdoctoral Fellowship by Scripps Institution of Oceanography. D.M.H. was supported by the New York University Abu Dhabi G1204, the NSF Office of Polar Programs ANT-0732869, and the NASA Polar Programs NNX12AB69G. E.P.G. was supported by the National Science Foundation (NSF) Division of Atmospheric and Geospace Sciences through Grant AGS1264195. C.Y. was funded by the Korea Meteorological Administration Research and Development Program under Grant KMIPA 2015-6110. The HadISST sea surface temperature and sea-ice concentration data were provided by the British Met Office, Hadley Centre. The ERA-Interim atmospheric reanalysis was provided by the European Centre for Medium Range Weather Forecasts (ECMWF). The comprehensive atmospheric model, CAM4, was made available by the National Center for Atmospheric Research (NCAR), supported by the National Science Foundation (NSF) and the Office of Science (BER) of the U.S. Department of Energy (DOE). The idealized atmospheric model, GFDL drydynamical-core, was developed by the National Oceanic and Atmospheric Administration (NOAA) at the Geophysical Fluid Dynamics Laboratory (GFDL). Computing resources were provided by the High Performance Computing (HPC) center at New York University (NYU) and the NCAR Yellowstone supercomputer. Three anonymous reviewers are thanked for their constructive comments, leading to a much improved manuscript.

\section{REFERENCES}

Ambrizzi, T., B. J. Hoskins, and H. H. Hsu, 1995: Rossby wave propagation and teleconnection patterns in the austral winter. J. Atmos. Sci., 52, 3661-3672, doi:10.1175/ 1520-0469(1995)052<3661:RWPATP>2.0.CO;2.
Bromwich, D. H., J. P. Nicolas, A. J. Monaghan, M. A. Lazzara, L. M. Keller, G. A. Weidner, and A. B. Wilson, 2013: Central West Antarctica among the most rapidly warming regions on Earth. Nat. Geosci., 6, 139-145, doi:10.1038/ngeo1671.

Clem, K. R., and R. L. Fogt, 2013: Varying roles of ENSO and SAM on the Antarctic Peninsula climate in austral spring. J. Geophys. Res. Atmos., 118, 11 481-11492, doi:10.1002/ jgrd.50860.

- , and -2015 : South Pacific circulation changes and their connection to the tropics and regional Antarctic warming in austral spring, 1979-2012. J. Geophys. Res. Atmos., 120, 2773-2792, doi: 10.1002/2014JD022940.

Dee, D. P., and Coauthors, 2011: The ERA-Interim reanalysis: Configuration and performance of the data assimilation system. Quart. J. Roy. Meteor. Soc., 137, 553-597, doi:10.1002/ qj.828.

Ding, Q., E. J. Steig, D. S. Battisti, and M. Küttel, 2011: Winter warming in West Antarctica caused by central tropical Pacific warming. Nat. Geosci., 4, 398-403, doi:10.1038/ngeo1129.

,,,-- and J. M. Wallace, 2012: Influence of the tropics on the southern annular mode. J. Climate, 25, 6330-6348, doi:10.1175/JCLI-D-11-00523.1.

Fogt, R. L., and D. H. Bromwich, 2006: Decadal variability of the ENSO teleconnection to the high-latitude South Pacific governed by coupling with the southern annular mode. J. Climate, 19, 979-997, doi:10.1175/JCLI3671.1.

— - , and K. M. Hines, 2011: Understanding the SAM influence on the South Pacific ENSO teleconnection. Climate Dyn., 36, 1555-1576, doi:10.1007/s00382-010-0905-0.

_ A. J. Wovrosh, R. A. Langen, and I. Simmonds, 2012: The characteristic variability and connection to the underlying synoptic activity of the Amundsen-Bellingshausen Seas low. J. Geophys. Res., 117, D07111, doi:10.1029/2011JD017337.

Gent, P. R., and Coauthors, 2011: The Community Climate System Model version 4. J. Climate, 24, 4973-4991, doi:10.1175/ 2011JCLI4083.1.

Held, I. M., and M. J. Suarez, 1994: A proposal for the intercomparison of the dynamical cores of atmospheric general circulation models. Bull. Amer. Meteor. Soc., 75, 1825-1830, doi:10.1175/1520-0477(1994)075<1825:APFTIO > 2.0.CO;2.

Holland, P. R., and R. Kwok, 2012: Wind-driven trends in Antarctic sea-ice drift. Nat. Geosci., 5, 872-875, doi:10.1038/ ngeo1627.

Hoskins, B. J., and D. J. Karoly, 1981: The steady linear response of a spherical atmosphere to thermal and orographic forcing. J. Atmos. Sci., 38, 1175-1196, doi:10.1175/1520-0469(1981)038<1179: TSLROA $>2.0 . C O ; 2$.

_, and T. Ambrizzi, 1993: Rossby wave propagation on a realistic longitudinally varying flow. J. Atmos. Sci., 50, 1661-1671, doi:10.1175/1520-0469(1993)050<1661:RWPOAR $>2.0 . C O ; 2$.

IPCC, 2013: Climate Change 2013: The Physical Science Basis. Cambridge University Press, 1535 pp, doi:10.1017/ CBO9781107415324.

Jacobs, S. S., and J. C. Comiso, 1997: Climate variability in the Amundsen and Bellingshausen Seas. J. Climate, 10, 697-709, doi:10.1175/1520-0442(1997)010<0697:CVITAA > 2.0.CO;2.

James, P. M., K. Fraedrich, and I. N. James, 1994: Wave-zonal-flow interaction and ultra-low-frequency variability in a simplified global circulation model. Quart. J. Roy. Meteor. Soc., 120, 1045-1067, doi:10.1002/qj.49712051812.

Jin, F., and B. J. Hoskins, 1995: The direct response to tropical heating in a baroclinic atmosphere. J. Atmos. Sci., 52, 307-319, doi:10.1175/1520-0469(1995)052<0307:TDRTTH >2.0.CO;2. 
Kaplan, A., M. Cane, Y. Kushnir, A. Clement, M. Blumenthal, and B. Rajagopalan, 1998: Analyses of global sea surface temperature 1856-1991. J. Geophys. Res., 103, 18567-18589, doi:10.1029/97JC01736.

Karoly, D. J., 1989: Southern Hemisphere circulation features associated with El Niño-Southern Oscillation events. J. Climate, 2, 1239-1252, doi:10.1175/1520-0442(1989)002<1239: SHCFAW $>2.0 . \mathrm{CO} ; 2$.

Knight, J. R., R. J. Allan, C. K. Folland, M. Vellinga, and M. E. Mann, 2005: A signature of persistent natural thermohaline circulation cycles in observed climate. Geophys. Res. Lett., 32, L20708, doi:10.1029/2005GL024233.

Lachlan-Cope, T., and W. Connolley, 2006: Teleconnections between the tropical Pacific and the Amundsen-Bellingshausen Seas: Role of the El Niño-Southern Oscillation. J. Geophys. Res., 111, D23101, doi:10.1029/2005JD006386.

Lefebvre, W., and H. Goosse, 2005: Influence of the southern annular mode on the sea ice-ocean system: The role of the thermal and mechanical forcing. Ocean Sci., 1, 145-157, doi:10.5194/os-1-145-2005.

,,-- R. Timmermann, and T. Fichefet, 2004: Influence of the southern annular mode on the sea ice-ocean system. J. Geophys. Res., 109, C09005, doi:10.1029/2004JC002403.

Li, X., D. M. Holland, E. P. Gerber, and C. Yoo, 2014: Impacts of the north and tropical Atlantic Ocean on the Antarctic Peninsula and sea ice. Nature, 505, 538-542, doi:10.1038/ nature12945.

— E. P. Gerber, D. M. Holland, and C. Yoo, 2015: A Rossby wave bridge from the tropical Atlantic to West Antartica. J. Climate, 28, 2256-2273, doi:10.1175/JCLI-D-14-00450.1.

Liu, J., J. A. Curry, and D. G. Martinson, 2004: Interpretation of recent Antarctic sea ice variability. Geophys. Res. Lett., 31, L02205, doi:10.1029/2003GL018732.

Pritchard, H. D., and D. G. Vaughan, 2007: Widespread acceleration of tidewater glaciers on the Antarctic Peninsula. J. Geophys. Res., 112, F03S29, doi:10.1029/2006JF000597.

— R. J. Arthern, D. G. Vaughan, and L. A. Edwards, 2009: Extensive dynamic thinning on the margins of the Greenland and Antarctic ice sheets. Nature, 461, 971-975, doi:10.1038/ nature 08471.

—, S. R. M. Ligtenberg, H. A. Fricker, D. G. Vaughan, M. R. van den Broeke, and L. Padman, 2012: Antarctic ice-sheet loss driven by basal melting of ice shelves. Nature, 484, 502-505, doi:10.1038/nature10968.

Raphael, M. N., and Coauthors, 2016: The Amundsen Sea low: Variability, change, and impact on Antarctic climate. Bull. Amer. Meteor. Soc., doi:10.1175/BAMS-D-14-00018.1, in press.

Renwick, J. A., and M. J. Revell, 1999: Blocking over the South Pacific and Rossby wave propagation. Mon. Wea. Rev., 127, 2233-2247, doi:10.1175/1520-0493(1999)127<2233:BOTSPA > 2.0.CO;2.

Sardeshmukh, P. D., and B. J. Hoskins, 1988: The generation of global rotational flow by steady idealized tropical divergence. J. Atmos. Sci., 45, 1228-1251, doi:10.1175/1520-0469(1988)045<1228: TGOGRF $>2.0 . \mathrm{CO} ; 2$
Schlesinger, M. E., and N. Ramankutty, 1994: An oscillation in the global climate system of period 65-70 years. Nature, 367, 723-726, doi:10.1038/367723a0.

Schneider, D., Y. Okumura, and C. Deser, 2012: Observed Antarctic interannual climate variability and tropical linkages. J. Climate, 25, 4048-4066, doi:10.1175/JCLI-D-11-00273.1.

Shepherd, A., and Coauthors, 2012: A reconciled estimate of icesheet mass balance. Science, 338, 1183-1189, doi:10.1126/ science. 1228102 .

Sigmond, M., and J. C. Fyfe, 2010: Has the ozone hole contributed to increased Antarctic sea ice extent? Geophys. Res. Lett., 37, L18502, doi:10.1029/2010GL044301.

Simpkins, G. R., S. McGregor, A. S. Taschetto, L. M. Ciasto, and M. H. England, 2014: Tropical connections to climatic change in the extratropical Southern Hemisphere: The role of Atlantic SST trends. J. Climate, 27, 4923-4936, doi:10.1175/ JCLI-D-13-00615.1.

Stammerjohn, S. E., D. G. Martinson, R. C. Smith, X. Yuan, and D. Rind, 2008: Trends in Antarctic annual sea ice retreat and advance and their relation to El Niño-Southern Oscillation and southern annular mode variability. J. Geophys. Res., 113, C03S90, doi:10.1029/2007JC004269.

Thompson, D. W. J., and J. M. Wallace, 2000: Annular modes in the extratropical circulation. Part I: Month-to-month variability. J. Climate, 13, 1000-1016, doi:10.1175/1520-0442(2000) 013<1000:AMITEC $>2.0 . \mathrm{CO} ; 2$

,-- , and G. C. Hegerl, 2000b: Annular modes in the extratropical circulation. Part II: Trends. J. Climate, 13, 1018-1036, doi:10.1175/1520-0442(2000)013<1018:AMITEC >2.0.CO;2.

- S. Solomon, P. J. Kushner, M. H. England, K. M. Grise, and D. J. Karoly, 2011: Signatures of the Antarctic ozone hole in Southern Hemisphere surface climate change. Nat. Geosci., 4, 741-749, doi:10.1038/ngeo1296.

Titchner, H. A., and N. A. Rayner, 2014: The Met Office Hadley Centre sea ice and sea surface temperature data set, version 2: 1. Sea ice concentrations. J. Geophys. Res. Atmos., 119 , 2864-2889, doi:10.1002/2013JD020316.

Turner, P. T., J. S. Hosking, G. J. Marshall, and A. Orr, 2013: The Amundsen Sea low. Int. J. Climatol., 33, 1818-1829, doi:10.1002/joc.3558.

Vaughan, D. G., G. J. Marshall, W. M. Connolley, J. C. King, and R. Mulvaney, 2001: Devil in the detail. Science, 293, 1777-1779, doi:10.1126/science.1065116.

_- and Coauthors, 2003: Recent rapid regional climate warming on the Antarctic Peninsula. Climatic Change, 60, 243-274, doi:10.1023/A:1026021217991.

Yoo, C., S. Lee, and S. B. Feldstein, 2012: Arctic response to an MJO-like tropical heating in an idealized GCM. J. Atmos. Sci., 69, 2379-2393, doi:10.1175/JAS-D-11-0261.1.

Yuan, X., 2004: ENSO-related impacts on Antarctic sea ice: A synthesis of phenomenon and mechanisms. Antarct. Sci., 16 415-425, doi:10.1017/S0954102004002238.

_ predictability. Geophys. Res. Lett., 28, 3609-3612, doi:10.1029/ 2001 GL012969. 